\title{
Usos y abusos del celular en adolescentes
}

\section{Uses and abuses of the cell phone in adolescents}

\author{
KU-ORTIZ, Analuisa*† \& AGUILAR-MORALES, Norma
}

Universidad Juárez Autónoma de Tabasco

ID 1er Autor: Analuisa, Ku-Ortiz / ORC ID: 0000-0002-5793-9399, Researcher ID Thomson: X-5099-2018, CVU CONACYT ID: 922401

ID 1er Coautor: Norma, Aguilar-Morales / ORC ID: 0000-0002-7292-3029, Researcher ID Thomson: K-8796-2018, CVU CONACYT ID: 4785542

DOI: $10.35429 / J I T .2019 .20 .6 .9 .13$

Recibido: 10 de Junio, 2019; Aceptado 30 de Septiembre, 2019

\section{Resumen}

Desde el comienzo del siglo XXI, el teléfono celular se ha convertido en un elemento esencial para la vida diaria ya que gracias a sus diversas funciones, aplicaciones y actualizaciones, han hecho que las actividades de nuestro día a día se vuelvan sencillas de realizar, desde llevar una agenda, hasta buscar información de forma rápida ahorrándose así un viaje por la biblioteca más cercana. El presente artículo tiene como principal objetivo exponer los usos ya sean personal o académicos del teléfono celular, y cómo esto puede dar paso al abuso excesivo del mismo y las consecuencias que puede provocar el abuso del mismo, entre las cuales se encuentra la dependencia excesiva a dicho dispositivo, ocasionando ansiedad y/o desesperación al momento de realizar tareas o cuando no se tiene el celular a la mano. En Zacatecas, México, se ha comprobado que el $80 \%$ de los accidentes automovilísticos son causados por hacer uso del celular mientras se conduce un auto, desplazando así al uso de alcohol y otras sustancias nocivas para la salud, además, está comprobado que conversar por un teléfono móvil cuando se maneja, aumenta hasta cinco veces más las probabilidades de ocasionar un percance vial, ya que absorbe de ocho a trece segundos de distracción en promedio responder una llamada o escribir un menaje por medio del celular. En conclusión, El uso del teléfono celular tiene beneficios, tanto personales como académicos o laborales, aunque también es importante inculcar la educación vial en los adolescentes, desde el hogar e incluso en las mismas instituciones ya que son más propensos a ser víctimas de algún accidente a causa del abuso excesivo del teléfono celular.

Uso de teléfonos celulares, Abuso de teléfonos celulares, Teléfonos inteligentes, Nuevas tecnologías, Procrastinación

\begin{abstract}
Since the beginning of the 21 st century, the cell phone has become an essential element for daily life because thanks to its various functions, applications and updates, they have made our day-to-day activities become simple to carry out, since carry out an agenda, until you find information quickly saving a trip to the nearest library. This article has as main objective to expose the uses, whether personal or academic, of the cell phone, how this can give way to excessive abuse of the same and the consequences that can cause the abuse of it, of which there is excessive dependence on said device, causing anxiety and / or despair when performing tasks or when the cell phone is not at hand. In Zacatecas, Mexico, it has been proven that $80 \%$ of car accidents are caused by using the cell phone while driving a car, thus displacing the use of alcohol and other massive substances for health, in addition, it is proven that Talking on a mobile phone when driving, increases the chances of causing a road accident up to five times and absorbs from eight to thirteen seconds of distraction on average answers a call or writes a message through the cell phone. In conclusion, the use of the cell phone has benefits, both personal and academic or work, although it is also important to instill road education in adolescents, from home and even in the same institutions that are more likely to be victims of an accident to Cause of excessive cell phone abuse.
\end{abstract}

Use of cell phones, Abuse of cell phones, Smart phones, New technologies, Procrastination

Citación: KU-ORTIZ, Analuisa \& AGUILAR-MORALES, Norma. Usos y abusos del celular en adolescents. Revista de Tecnologías de la Información. 2019. 6-20: 9-13

\footnotetext{
* Correspondencia del Autor (analuisaku21@gmail.com)

$\dagger$ Investigador contribuyendo como primer autor.
} 


\section{Introducción}

El uso de nuevas tecnologías ha crecido de forma exuberante en los últimos años, es increíble ver cómo ha evolucionado, tanto que los celulares inteligentes o Smartphone han reemplazado muchos artefactos que solían ser de utilidad en la vida diaria hace unos cuantos años, desde libros, hasta cámaras fotográficas o de video e incluso ha revolucionado la simple forma de comunicarse, ahora podemos interactuar con otras personas no solo por llamada, sino también por notas de voz o video llamadas, el problema más bien surge cuando el uso del celular se transforma en abuso, generando una dependencia extrema del mismo, e incluso la adicción, siendo los jóvenes los principales dependientes de dicho artefacto y también los afectados en las consecuencias que puede traer el uso inadecuado del mismo.

\section{Método}

El presente trabajo es producto de una investigación documental en donde se analizaron diversas fuentes impresas $y$ electrónicas para obtener datos acerca del uso del celular en adolescentes y poder llegar a conclusiones que hagan una aportación sobre el tema.

\section{Contenido}

Es increíble ver cómo ha evolucionado el teléfono celular, desde sus inicios en 1973 cuando Martin Cooper creó el primer radioteléfono capaz de enviar la voz a través de radiofrecuencias sin ser necesaria la utilización de cables en el proceso, imitando así la transmisión de ondas de radio, pero no es hasta 1979 que el teléfono celular se convierte en la nueva opción inalámbrica y dinámica para usuarios de los nuevos servicios telefónicos (Pañuela, et al. 2014), sin embargo, con la aparición del Smartphone en 1997, pasó de ser un dispositivo de uso único para realizar llamadas y recibirlas, a uno donde además se puedan enviar y recibir mensajes, notas de voz, video llamadas, crear y editar fotos, videos, reproducir música, jugar videojuegos, realizar compras, consultar cuentas bancarias, navegar por internet, hacer uso del GPS, consultar diversas redes sociales, entre otras actividades. Sin embargo, contar con tan atractivas funciones en un solo dispositivo móvil ha sido clave no sólo para su uso personal, sino también como distractor para las actividades a realizar.
La generación actual de jóvenes universitarios tiene acceso a estas tecnologías de forma fácil, de hecho, es en la adolescencia cuando los jóvenes comienzan a interactuar en mayor medida con dispositivos móviles (Malo, 2006), con referencia a ello, el último estudio del Instituto de Estadística y Geografía [INEGI] (2018) sobre usos del celular, describe que en México el $73.5 \%$ de la población de seis años o más hace uso de esta tecnología; por lo tanto las nuevas generaciones comienzan a utilizar los teléfonos celulares desde edad temprana.

A su vez, cuando el uso se convierte en abuso, da paso a efectos en su mayoría severos, los jóvenes de hoy en día se han visto en múltiples ocasiones en apuros por no poder hablar y establecer alguna relación amistosa, romántica o laboral con otras personas de forma presencial, a menos que se lleve a cabo por medio del teléfono móvil utilizando un sistema de mensajes de texto, video llamada y/o redes sociales, es ahí cuando el celular pasa de ser un simple artefacto, a ser parte de nosotros.

Otra consecuencia que se genera en la mayoría de los jóvenes es cuando el abuso va más allá y se transforma en adicción, esto se logra identificar en la conducta que expresan los jóvenes, desde ignorar a otras personas durante una conversación por estar usando el celular, interfiriendo así en la interacción personal cara a cara con otras personas y no solamente con ellas, sino con el entorno que le rodea, esto es conocido como phubbing (Barrios, Bejar y Cauchos, 2017); a lo mencionado anteriormente, por consecuencias del abuso excesivo de esta tecnología se anexan otro tipo de patologías, como son la depresión, ansiedad por no tener a la mano el celular, falta de atención y comportamiento violento hacia los demás.

De acuerdo con el Instituto Mexicano del Seguro Social [IMSS] (2018), es la edad de 13 a 22 años la etapa en la que se desarrolla una mayor adicción al uso de los aparatos electrónicos, en donde también puede influir factores como la baja autoestima y la necesidad de aceptación, no solamente puede repercutir en el ámbito personal de los jóvenes, sino también en su desempeño laboral. 


\section{La vida universitaria}

Cuando los jóvenes comienzan su vida de universitarios, experimentan nuevas responsabilidades, actividades y un estilo de vida muy diferente al que tenían antes de iniciar esa etapa. Al ser tareas en su mayoría demandantes, comienzan a buscar vías de escape que les permita sentirse relajados en lugar de angustiados o ansiosos, provocando así que se sientan desmotivados y sin la energía y el interés necesarios para realizar sus actividades académicas, por estas razones, han optado por dedicar gran parte de su tiempo al uso de este dispositivo.

Jasso, López y Díaz (2017), determinan que la edad es un factor clave en lo que respecta a la adicción al internet al igual que al teléfono celular. Los estudiantes universitarios son quienes implementan en gran medida el uso del internet y las nuevas tecnologías en su vida diaria, relacionándose así con el estrés académico, pasatiempos, entre otras actividades. Para un adolescente estar conectado todo el día a sus redes sociales, ver videos $\mathrm{y}$ jugar videojuegos o escuchar música por medio del celular es una actividad que lo relaja, pero a su vez, su desempeño académico se ve afectado, ya que, al invertir tiempo en el uso tan inadecuado del mismo, reduce el espacio necesario para realizar sus actividades académicas, las cuales requieren de tiempo, dedicación, pero sobretodo el sentido de responsabilidad para llevarlas a cabo.

Además de interferir en el tiempo para realizar dichas actividades, el uso abusivo de dicho artefacto puede llegar a afectar la vida escolar y personal del estudiante. Años atrás, los profesores se quejaban de que los estudiantes se distraían mucho platicando con los compañeros que se sentaban a su lado o dibujando en su cuaderno en lugar de prestar atención a clase, ahora las quejas van dirigidas al uso inadecuado del celular en clase, ya que en vez de ser utilizado como herramienta para la misma clase la utilizan para entretenerse, sin embargo, muchos docentes han optado por dejar pasar estas situaciones para evitar problemas con los padres, ya que aunque suene increíble, la mayoría de los jóvenes de hoy en día no son capaces ni de abogar por ellos mismos, aún tienen la necesidad de que sus padres los protejan y defiendan.
Como se mencionaba con anterioridad, los estudiantes buscan actividades que los relajen consideradas como una vía de escape para las actividades correspondientes con su vida universitaria, esto nos lleva a la procrastinación digital. La procrastinación es considerada como la acción de retrasar voluntaria e innecesariamente la realización de tareas al punto de experimentar malestar subjetivo (Clarina, Cladellas, Badía y Gotzens, 2011; Solomon y Rothblum, 1984), es también conocido como la acción de postergar o dejar todo para el día siguiente; la procrastinación digital entonces, puede ser definida como la postergación de tareas o actividades por medio del uso de tecnologías y el internet.

Ramos, et. Al. (2017), explican la relación entre procrastinación, rendimiento académico y adicción al internet en una muestra de estudiantes universitarios de Quito, Ecuador, y determinan que los estudiantes que presentan altos niveles de procrastinación suelen invertir la mayor parte de su tiempo en revisar las bandejas de entrada de las aplicaciones instaladas en el teléfono celular, a pesar de no haber sido alertados por el mensaje o notificación del mismo.

Sin embargo, no todo es malo, Hernández, Capetillo y Soto (2017) argumentan que "el uso del celular y aplicaciones en los centros educativos no es negativo en sí mismo ya que representan una potente herramienta para compartir información, dialogar y mantener relaciones" (p.3), actualmente, existen un sinfín de aplicaciones que son sumamente útiles para estudiar y que pueden ser empleadas en medio de la clase.

El teléfono celular, por el gran avance tecnológico que ha tenido, ha sido también de gran ayuda para los estudiantes, ya que, desde este artefacto, los estudiantes pueden leer libros electrónicos, ver videos relacionados a los temas vistos en clase, tomar fotografías y videos como evidencias y hasta pueden hacer uso de aplicaciones educativas ya sea para practicar un nuevo idioma, tomar cursos e incluso tomar anotaciones o crear presentaciones para la clase. 


\section{El uso inadecuado del teléfono celular}

El teléfono celular se ha convertido en un artefacto que sobrepasa más allá de su utilidad como herramienta de comunicación, se ha confirmado que su uso excesivo conlleva a la adicción, sobre todo en adolescentes, Jiménez (2010) explica que los jóvenes que están en la edad de 14 y 16 años se encuentran en una etapa donde "se inician la mayor parte de conductas de riesgo y algunos problemas de salud, en la cual la personalidad aún no está suficientemente definida. Por lo que son más vulnerables e influenciables para la adquisición de determinados hábitos" (p.461), ocasionando no sólo que el desempeño escolar del estudiante disminuya, sino que también ocasione accidentes viales; está comprobado que "conversar por un teléfono móvil cuando se maneja, aumenta hasta cinco veces más la posibilidad de provocar un percance vial ya que absorbe de ocho a trece segundos de distracción en promedio responder la llamada o mensaje" (Martínez, S. 2012, citado por García y Fábila, 2014, p. 4).

En Zacatecas, México, se han realizado estudios que demuestran que "utilizar el teléfono celular mientras se conduce se ha convertido en la principal causa de muerte por accidentes automovilísticos desplazando el consumo de alcohol y drogas, aproximadamente el $80 \%$ de los percances viales en la entidad de personas entre 14 y 30 años ocurren por esta causa (Villagrana, 2011 citado por García y Fábila, 2014, p. 4).

El uso inadecuado de esta herramienta no solo atrae peligros para el conductor, sino también para el peatón, ya que también supone un riesgo para su seguridad, como por ejemplo cruzar las calles a la vez que se revisa el celular. Stavrinos (2011) citado por el Instituto Nacional de Salud Pública (2019a) argumenta que "existen estudios realizados en ambientes de realidad virtual que han mostrado que usar el teléfono móvil eleva la distracción de los peatones a un nivel que los pone en riesgo". Según el Instituto Nacional de Salud Pública (2019b), las distracciones causadas por el uso del teléfono celular pueden ser visuales, cognitivas, físicas y auditivas. Una investigación realizada en estudiantes de Medicina de la Universidad de Carabobo en Venezuela indica que el $96 \%$ de los jóvenes estudiantes tiene conocimientos sobre el riesgo que conlleva hacer uso del celular mientras se conduce un auto,

\section{Conclusiones}

El número de teléfonos móviles crece de manera extravagante con el paso de los años, el contar con un teléfono celular ya no es solo permitirse un lujo, sino más bien se ha convertido en una necesidad. Las personas, en especial los jóvenes se han vuelto dependientes de dicho artefacto, al grado de que artículos como relojes despertadores, televisión, cámaras fotográficas y de video, libretas, libros, entre otros, han sido reemplazados por un solo dispositivo, incluso ha invadido la capacidad que solíamos tener para recordar números de teléfono.

Si bien, su uso puede traer beneficios, tanto personales como académicos o laborales, las instituciones por ejemplo han optado por la creación de plataformas virtuales para la realización de tareas, incluso los profesores optan por utilizar material multimedia para impartir sus clases, sin embargo, suele suceder que al estar en contacto tanto tiempo con estos dispositivos y más utilizándolo para propósitos académicos, puede generar ansiedad y/o desesperación al momento de realizar tareas, es por eso que la mayoría de los jóvenes opta por buscar una "vía de escape" para dichas actividades, he ahí la procrastinación digital.

Contreras et al. (2011) explican que gracias al internet, los jóvenes universitarios tienen acceso a un sinfín de páginas web donde pueden realizar actividades atractivas que les generan una satisfacción inmediata, generando así la postergación de actividades, esto argumenta el hecho de que los estudiantes con mayores niveles de procrastinación empleen la mayor parte de su tiempo libre en redes sociales $\mathrm{y}$ aplicaciones de audio y video, que generan satisfacción al usarlas.

Sin embargo, como se mencionaba con anterioridad, los jóvenes corren el peligro de ser víctimas de algún accidente a causa del abuso del teléfono celular, desde algo tan "pequeño" como tropezarse, hasta por accidentes de mayor magnitud como un accidente automovilístico por ejemplo. Por lo mismo, es importante inculcar la educación vial en los adolescentes, desde el hogar e incluso en las mismas instituciones. 


\section{Referencias}

Barrios, D., Bejar, V., y Cauchos, V. (2017). Uso excesivo de Smartphones/teléfonos celulares: phubbing y nomofobia. Revista chilena de neuropsiquiatría. 55(3) 205-206. doi.org/10.4067/s0717-92272017000300205

Clariana, M., Cladellas, R., Badia, M. y Gotzens, C. (2011). La influencia del género en variables de la personalidad que condicionan el aprendizaje: inteligencia emocional y procrastinación académica. REIFOP, 14(3) 87$96 . \quad$ Recuperado de: https://core.ac.uk/download/pdf/78542870.pdf

Contreras, H., Mori, E., Lam, N., Gil, E., Hinostroza, W., Rojas, D., et al. (2011). Procrastinación en el estudio: exploración del fenómeno en adolescentes escolarizados. Revista Peruana de Epidemiología, 15(3), 1-5. Recuperado de: http://www.redalyc.org/pdf/2031/20312277100 7.pdf

García, V. y Fabila, A. M. (2014). Nomofilia vs nomofobia, irrupción del teléfono móvil en las dimensiones de vida de los jóvenes, un tema pendiente para los estudios en comunicación. Razón y palabra. 86. 1-19. Recuperado de: http://www.redalyc.org/pdf/1995/19953072804 8.pdf

Hernández, O., Capetillo, C., y Soto, E. (2017). Uso de teléfonos celulares inteligentes en estudiantes de preparatoria y su influencia en el rendimiento académico. Revista digital FILHA. $17 . \quad 1-15-$ Recuperado de: http://www.filha.com.mx/upload/publicaciones/ archivos/20171229194621_uso_de_telefonos_c elulares.pdf

Instituto mexicano del seguro social (2018). La adicción a las nuevas tecnologías provoca ansiedad y desmemoria, advierten especialistas del IMSS. Imss. Recuperado de: http://www.imss.gob.mx/prensa/archivo/20180 $8 / 202$

Instituto nacional de estadística y geografía (2019). Comunicado de prensa, encuesta nacional sobre disponibilidad y uso de tecnologías de la información en los hogares, 2018. INEGI. 1-19. Recuperado de: https://www.inegi.org.mx/contenidos/saladepre nsa/boletines/2019/OtrTemEcon/ENDUTIH_20 18.pdf
Instituto Nacional de Salúd Pública (2019). Usos de celulares y seguridad vial. Recuperado de: https://www.insp.mx/avisos/3623-seguridadvial.html

Jasso, López y Díaz (2017). Conducta adictiva a las redes sociales y su relación con el uso problemático del móvil. Psychological research records. 7, 2832-2838. Recuperado de: https://reader.elsevier.com/reader/sd/pii/S20074 71917300546?token=7D12E03087B53830B48 ED05959CED835437D71D96B047D34093757 513C628C483F70E57CB4CC3FE1B05F3CC5 E1D3D0B1

Jiménez, J. (2010). Adolescencia y prevención de accidentes de tráfico. Unidad de medicina de familia y comunitaria. 42(9) 459-462. Doi: 10.1016/j.aprim.2010.06.002

Malo, S. (2006). Impacto del teléfono móvil en la vida de los adolescentes entre 12 y 16 años. Revista científica de comunicación y educación, 105-112. ISBN: 1134-3478 Recuperado de: file:///C:/Users/Usuario/Downloads/DialnetImpactoDelTelefonoMovilEnLaVidaDeLosAdo lescentesEn-2089274.pdf

Pañuela, M., Paternina, J., Moreno, D., Camacho, L., Acosta, L., y De León, L. (2014). El uso de los Smartphones y las relaciones interpersonales de los jóvenes universitarios en la ciudad de Barranquilla, Colombia. Salud uninorte. 30(3) 335-346. ISSN: 0120-5552

Ramos, C., Jadán, J., Paredes, L., Bolaños, M., y Gómez, A. (2017). Procrastinación, adicción al internet y rendimiento académico de estudiantes universitarios ecuatorianos. Estudios pedagógicos. 43(3), 275-289. Doi: $10.4067 /$ S0718-07052017000300016

Solomon, L. y Rothblum, E. (1984). Academic procrastination: frecuency and cognitivebehavioral correlates. Journal of counseling psychology. 31(4) 503-509. doi: 10.1037/00220167.31.4.503 